УДК 821.161 .1

\title{
С.B. Вировец
}

\section{СПОРЫ О ПОЛИТИКЕ АНГЛИИ И ФРАНЦИИ НА СТРАНИЦАХ РУССКИХ ЖУРНАЛОВ 1860-1862 ГГ. И ПОЗИЦИЯ ЖУРНАЛА БРАТЬЕВ ДОСТОЕВСКИХ «ВРЕМЯ»}

\author{
Исследование выполнено при финансовой поддержке РФФИ в рамках научного проекта № 18-012-90020\18. \\ Реконструируется образ Англии и его функции в журнале братьев Достоевских «Время», также он исследуется в контексте \\ английской проблематики журналов «Отечественные записки», «Русский вестник» и «Современник». Показано, что образ \\ Англии во «Времени» становится инструментом в полемике с названными журналами: характерные черты образа, упоми- \\ наемые в названных журналах, трансформируются с целью развенчать сложившееся у отечественного читателя представ- \\ ление об Англии и Европе в целом. \\ Ключевые слова: Ф.М. Достоевский; почвенничество; «Время»; «Отечественные записки»; «Русский вестник»; «Совре- \\ менник»; образ Англии; образ Франции; Европа.
}

Актуальность данного исследования определяется установкой на реконструкцию образа Англии как части общей картины мира Ф.М. Достоевского. На данный момент исследований, посвящённых системному изучению образа Англии в публицистике Достоевского, в частности в журнале «Время», нет. При этом Англия часто упоминается на страницах журнала, а исследователи отмечают, что английская культура, наука и философия, так или иначе, были осмыслены писателем и отразились в его творчестве ${ }^{1}$.

Цель данного исследования - реконструировать образ Англии, определить его функции в журнале М.М. и Ф.М. Достоевских «Время» с 1860 по 1862 г. и выявить, как изменился образ Англии по сравнению с уже сложившимся благодаря журналам «Современник», «Отечественные записки» и «Русский вестник» представлением о ней. Хронологические рамки обусловлены тем, что после возвращения из ссылки в 1859 г. Достоевский мог составить своё представление об Англии только из художественной литературы или отечественной публицистики. На страницах «Времени», который Достоевские начинают издавать в 1861 г., Ф.М. Достоевский часто полемизирует с журналами «Отечественные записки», «Русский вестник» и «Современник». Это указывает на то, что Федор Михайлович активно интересовался их содержанием. В рамках полемики образ Англии обретает определённые функции, поэтому данный период (1861-1862 гг.) также нуждается в рассмотрении. После 1862 г. Ф.М. Достоевский, побывав в Европе, меняет свое представление об Англии, соответственно, меняется и функция образа Англии, и сам образ, что должно стать темой для отдельного исследования.

Обращение к образу Англии связано в том числе со специфической позицией журнала «Время». Достоевский, будучи в ссылке, тяжело переживал изоляцию, невозможность следить за новыми тенденциями общественной жизни. Включиться в «сложные общественные отношения и настроения» [6. С. 35] Достоевскому один из первых помогал его старый другпетрашевец А.Н. Плещеев, а по возвращении в Петербург писатель начинает общаться с А.П. Милюковым. Идеи Плещеева и Милюкова оказали большое влия- ние на Достоевского и во многом способствовали формированию идеологической позиции писателя почвенничества. Плещеев в письмах к писателю подчёркивал, что в России в эпоху преобразований действуют две партии: одна, «плантаторская», действует в узких сословных интересах, а другая предлагает исключительно умозрительные решения вопроса, не имеющие ничего общего с реальностью. В свою очередь, кружок, собиравшийся у Милюкова, обсуждал новое положение Европы относительно России: гуманные идеи Западной Европы не оправдали себя, и во всей Европе царит реакция, в то время как в России наконец наступает эпоха перемен. Обе идеи нашли отражение в журнале Достоевских «Время», ставшем печатным органом почвенников [6. С. 35-38].

В объявлении на подписку, написанном Ф.М. Достоевским, подчёркивается, что журнал не имеет ничего общего с западничеством или славянофильством. «Время» призывает к воссоединению образованных слоёв общества и народа и выработке своего собственного, самобытного пути, по которому пойдёт Россия [Там же. С. 40]. Заявив о своей идеологической позиции, журнал включается в полемику с публицистами, считающими необходимым следовать не просто по пути Западной Европы, но Англии как лучшего образца гуманистических европейских идей.

В начале 1860-х гг. Англия оказывается в центре внимания русских публицистов в связи с двумя вопросами: освобождение Италии и вопрос колонизации.

В данный период Россия вступила в полосу революционного кризиса: назрела необходимость реформ во всех сферах общественной жизни, остро встал вопрос крестьянского восстания. В решении данных задач русская общественность возлагала большие надежды на Александра II, однако он их не оправдал. На фоне разочарования в проводимых царём реформах публицисты были сильно впечатлены освободительным движением в Италии и войной Севера и Юга в Америке [7. С. 69].

Движение, направленное на освобождение от иноземных захватчиков и объединение Италии в единое государство, возникло в конце 1859 г. Часть областей, принадлежавших папе, не могла присоединиться к 
движению из-за реакции, поддерживаемой в основном войсками Франции, которая, в свою очередь, претендовала на присоединение Савойи. Единственной державой, способной обуздать амбиции Франции, была Англия. Таким образом, в 1861 г. на мировой арене были два крупнейших игрока, от результата противостояния которых зависела судьба Италии. Соответственно, именно они стали главными героями мировой прессы.

В России журналистика конца XIX в. имела свои особенности: многие печатные органы представляли собой кружок единомышленников, придерживающихся определённой политической позиции. Единомышленники, объединённые журналами, были, как правило, либо западниками (либералами), либо славянофилами. Третью позицию обозначили в своих журналах братья Достоевские - почвенничество. Каждый из журналов транслировал своё видение путей развития России. Вторая особенность журналистики второй половины XIX в. была обусловлена жёсткой цензурной политикой. Журналы, названные выше, считая невозможным не занимать какую-либо политическую позицию и опасаясь при этом цензуры, часто использовали примеры из современной общественной жизни других стран, а также из их истории, чтобы критиковать или, наоборот, косвенно выразить одобрение действиям правительства.

Данные особенности публицистики оказали влияние на представление об Англии, которое сформировалось в сознании Достоевского, в том числе под влиянием данных журналов.

Противостояние Англии и Франции отразилось в русской публицистике в статьях, посвящённых политическим новостям, по принципу контраста: «Русский вестник», «Современник» и «Отечественные записки» сравнивают Англию и Францию.

Настаивающая на либеральном курсе для России редакция журнала показывает Англию как страну, где индивидуальная свобода человека ценится превыше всего. В январе 1860 г. становится известно о запрете во Франции католической газеты l'Univers. «Русский вестник», освещая данный факт, отмечает, что редакция l'Univers была вынуждена «перенести свои станки в ненавистную протестантскую Англию <..> и уже оттуда метать ватиканские перуны в союзе с ирландскими ультрамонтанами, которые пользуются совершенной безопасностью и полной свободой изрыгать свои хуль на свободу (курсив мой. - С.В.)» [8. С. 84].

Францию «Русский вестник» представляет, напротив, негуманной и беспринципной. Стремление Франции получить власть над частью территорий Италии расценивается и некоторыми французами, и «Русским вестником» как предательство гуманистических идеалов ради выгоды. Редакция приводит в статье слова французского публициста: «Прилично ли Франции с её преданностью абсолютным принципам, теории человеческих прав, равенству, утверждать, что в одном месте народ имеет право установлять себе правительство, а в другом, в нескольких шагах от прежнего, он теряет это право ради интересов большинства и исторических преданий?» [Там же. С. 88].

Одной из лучших черт Англии в рамках итальянского вопроса редакция «Русского вестника» считает приверженность своим принципам: «<..> Но и без объяснения всякому очевидно, что Англия не только не последовала за другой державой, но, напротив, заставила свою союзницу следовать за собой и действовать в духе её начал. Она доказала ясно, что готова защищать эти начала всей своей силой, и что, следовательно, они непобедимы» [8. С. 107].

«Современник», которому удавалось выдерживать революционно-демократическое направление, так же, как и «Русский вестник», противопоставляет Англию и Францию. В февральском политическом обзоре 1860 г. [9. С. 303-322] указывается на лицемерие Франции, которая согласилась не вмешиваться в дела Италии только для того, чтобы выказать уважение свой более сильной сопернице - Англии. В то же время редакция сообщает, что степень вмешательства самой Англии в дела итальянского народа оказалась достаточно велика: итальянцы могут рассчитывать на успех благодаря Кавуру, который возглавил министерство с его помощью. «Современник» поддерживает политику Англии, потому что Кавур, по мнению редакции, способен привести освободительное народное движение к победе, и таким образом Англия оказывает услугу будущей объединённой Италии. В «Современнике» Англия - страна, сочувствующая угнетённому народу, а также ставящая благо своего народа превыше всего. Редакция одобряет нежелание Англии, несмотря на сочувствие жителям Савойи, вступать из-за неё в войну: «Конечно, одна только Англия имела бы теперь силу остановить французские притязания на Савойю вооружённой рукой. Но английские министры положительно объявили, что не намерены жертвовать деньгами и кровью англичан поэтому делу, которое не касается прямых интересов Англии. Они будут протестовать, выразят своё неудовольствие, но больше этого не захотят ничего сделать, если сам Пьемонт не имеет решимости мешать насильственному присоединению Савойи к Франции. $<\ldots>$ Итак, спор собственно идёт между Сардинией и Францией. < ..> Поэтому английские государственные люди полагают, что присоединение Савойи к Франции неизбежно» [Там же. С. 308].

«Отечественные записки» - это журнал, по сути, либеральный. В основе политики Англии «Отечественные записки», так же, как и «Русский вестник», склонны видеть далёкие от меркантильных мотивов побуждения. Так, горячо поддерживается стремление Англии следовать принципу невмешательства несмотря на осуждение на европейской арене.

В целом в «Русском вестнике», «Отечественных записках» и «Современнике» формируется образ Англии как либеральной гуманной державы, для которой главную ценность представляют народ и индивидуальные права каждого человека. Данные качества выявляются в контрасте с беспринципной, беззастенчиво пользующейся своей силой Францией. Наиболее ценным качеством Англии, по мнению отечественных публицистов, является рациональный гуманизм.

В мае 1860 г. итальянский вопрос был временно забыт из-за разгоревшегося в то время восстания в Сицилии. Это восстание, говорит редакция «Отечественных записок», Англия пыталась предотвратить, однако французские публицисты вновь Англию, из- 
вестную, по их мнению, своей «зажигательной» политикой, виновницей произошедшего.

Редакция журнала не допускает мысли о правдивости данных предположений. В качестве оправдания Англии выдвигается всем известное английское благоразумие: англичане не будут спонсировать разжигание мятежа, если он не принесёт им пользы [10. C. 56]. Становится ясно, что Англия готова оберегать свои ценности лишь в том случае, если не потерпит от этого убытки. Тот же принцип державы прослеживается в вопросе колонизации.

Автор февральской статьи «Современника» 1860 г. «Леность грубого простонародья» критикует доводы в пользу эксплуатации крепостного труда [11. С. 227]. Для их опровержения «Современник» приводит перевод статьи из журнала Edinburgh Review.

Она начинается с описания нравственных и физических страданий работников плантаций. Автор даёт подробную статистику наказаний, смертности и рождаемости среди рабов, а также уровень продуктивности труда и прибыли. Делается вывод, что по всем показателям рабовладение, прежде всего, невыгодно. В этом позиция автора английского журнала и автора статьи «Современника» совпадает: и тот, и другой делают акценты на выгоде и экономической прибыли. Подробно описываются и плоды освобождения; с отменой рабства афроамериканцы начинают превращаться в «цивилизованный» народ: они строят каменные дома со спальнями и гостиными, «передней части участка дают вид европейского садика» [Там же. C. 260], мужчины ходят в чистых опрятных костюмах, а женщины в платьях.

Статья англичанина заканчивается словами: «Вместо того, чтобы быть мучением государственных людей, позором Англии - Вест-Индия теперь становится бесценным сокровищем британской короны. Великое дело освобождения доказало, что поступать справедливо есть высшая степень расчётливости (курсив мой. - C.B.)» [Там же. С. 262]. Принципиально важно, что факт освобождения рабов с целью обогатиться, а не из человеческого сочувствия, редакция «Современника» полностью одобряет и считает нужным освободить крестьян в России на тех же основаниях.

«Отечественные записки» также придерживаются данной позиции. В майском номере журнала в обзоре повести, посвящённой Новой Зеландии, подчёркивается, что именно англичане первые перестали обращать в рабов жителей земель, которые покоряли. Подобная политика понравилась далеко не всем: многие европейцы претендовали на эти земли, однако англичане дали понять, что попытки обмануть туземцев будут дорогого стоить державам [12. С. 40-42]. «Отечественные записки» также предлагают читателям в рамках политического обозрения перевод статьи из одного из английских еженедельных изданий, посвященную поездке принца Валлийского в Канаду, где говорится: «Мы давно отказались не только от покушений, но даже и от желания подчинить наши колонии мелочным интересам торговой монополии. Мы теперь смотрим на них так, как следует смотреть, как на частицы величия англо-саксонской расы...» [13. C. 85-86].
При этом редакция «Отечественных записок» воздерживается от оценки известных примеров излишней жестокости англичан по отношению к коренному населению колоний в условиях военного конфликта.

В одном из обзоров иностранной литературы исследуется «Мой дневник в Индии» Уильяма Росселя, в котором он описывает «безрассудную и нехристианскую мстительность» англичан по отношению к индийцам во время подавления восстания сипаев [14. С. 4]. Россель испытывает симпатию к туземцам и жёстко критикует соотечественников за дискриминацию из-за цвета кожи и культурных различий. Он говорит о том, что англичане страшные деспоты, когда находятся на большом расстоянии от дома, а значит, от «бича общественного мнения и гласности» [Там же. С. 11].

«Отечественные записки», используя данный материал, акцентируют внимание читателя на том, что английская пресса, обладающая полной свободой слова, становится совестью английской нации и одним из столпов гуманистического, развитого государства.

При этом английские исследователи XIX в., а вслед за ними «Отечественные записки», отмечали признаки нравственного упадка в английском обществе. В разделе, посвящённом иностранной литературе, в переводе работы «О свободе» Стюарта Милля [15. С. 1-9] говорится, что отсутствие личности главный порок европейского (в том числе английского) общества. Уравнение всех во всём считается высшей целью развития, главным достижением человечества.

Милль указывает на то, что стремление к стандартизации лишает людей индивидуальности, оригинальности мышления, подчас даже самой способности мыслить. Автор называет это «тиранией большинства». По его мнению, настроениями массы, которая как раз является продуктом усреднения и представляет из себя посредственность в чистом виде, управляют не книги или достойные люди, а личности во всём на неё (массу) похожие. Единственным «лекарством» от этой «болезни» является способность людей, стоящих у власти, прислушиваться к более талантливым и оригинальным советникам. Милль подчёркивает: «Все благородные начинания идут от отдельных лиц, по большей части от одного лица» [Там же. С. 3].

Живой интерес русских публицистов к политической и общественной жизни европейских держав, их государственному устройству был вызван необходимостью решить, по какому принципу будет проводить свои реформы Россия: пойдёт ли она по европейскому пути или найдёт собственный. Благодаря итальянскому вопросу кумиром русского передового общества стала Англия. Публицисты, стремясь указать царю «правильный» путь реформирования, создали на страницах журналов образ гуманной страны, в которой человек и в целом народ являются высшей ценностью. Также Англия, согласно ви́дению журналов, сочетает гуманность с рациональностью: жизнь и достаток англичанина для неё приоритетны. Статьи, в которых обнажаются пороки английского общества, комментариями редакции не сопровождались и, по 
всей видимости, были опубликованы с исключительно ознакомительной целью.

Ф.М. Достоевский считал, что нельзя полагаться на опыт Англии и любой другой европейской державы в вопросах реформирования. Главной опасностью, по его мнению, является принятие идеи рационального гуманизма. Аргументация данной позиции становится ключевой задачей первого номера журнала М.М. и Ф.М. Достоевских «Время».

В первой части программного произведения «Ряд статей о русской литературе. Введение» Ф.М. Достоевский отмечает, что задача России - это синтез европейских идей и поиск своего пути развития. Для того, чтобы донести данную мысль до читателя, Достоевский в том числе использует уже знакомую читательской публике оппозицию Англия - Франция.

Русские публицисты утверждали принципиальную разницу между двумя нациями. Достоевский преследует цель развенчать данное убеждение, поэтому разрушает оппозицию, утверждая мысль о том, что обе страны схожи между собой больше, чем кажется: «Англичанин до сих пор еще не в состоянии допустить разумности существования Француза; Француз платит ему совершенно той же монетой, даже с процентами, несмотря ни на какие союзы, ententes cordiales и проч. и проч. А между тем и тот, и другой - европейцы, настоящие, главные европейцы, представители европейцев» [16. С. 6].

Главное свойство всех европейцев - стремление к национальному индивидуализму. Желание отделиться настолько сильно, что порождает агрессию, которая делает невозможным гуманное отношение к другим народам. В первом «Политическом обзоре» январского номера об Англии говорится: «С вершины Гибралтарской скалы она давно ревниво надзирает за проливом: из двух сторон его она снисходительно соглашается владеть только одной, но никак не хочет допустить мысли, чтобы другая сторона принадлежала какой-нибудь другой европейской державе. Французский ли флот явится перед Тангером, как это было 15 лет назад, - Англия негодует. Испания ли хочет наказать разбойников - Англия начинает её стращать... (курсив мой. - C.B.)» [17. С. 2]. Так Англия Достоевского, в отличие от Англии, образ которой был создан в других журналах, антигуманна.

Показной, приносящий выгоду гуманизм также оказывается порождением индивидуализма и, по мнению «Времени», направлен исключительно на извлечение выгоды из чужого страдания. Для утверждения данной идеи Англия, имевшая славу заступницы слабых народов, приравнивается к всегда агрессивно настроенной Франции.

Англия и Франция вновь сталкиваются в рамках сирийского вопроса, который возник из-за массового убийства христиан. На европейском совете было решено ввести в Сирию французские войска для обеспечения безопасности христианского населения. Согласившись с данным решением, Англия делает все возможное, чтобы Франция не имела влияния в Сирии, несмотря на то, что христиане, там живущие, возлагают на французов большие надежды. Морская держава игнорирует данный факт, так как имеют место прагмати- ческие мотивы: Сирия лежит на пути в Индию, и здесь же создается Суэцкий перешеек. Франция также не заботится об оставляемых ими христианах: «Но отступление из Сирии нисколько не сконфузит французов. Они сочинят по этому поводу несколько песен, устроят торжественный приём для возвращающихся войск и потом взапуски будут прославлять свои подвиги на Востоке <..> Между тем в Сирии слух скором выступлении французов навел уныние на всё тамошнее европейское и христианское население, а турки, напротив, очень рады» [18. С. 3]. Так редакция, сравнив державы с точки зрения следования гуманным идеалам, нивелирует разницу между ними в данном аспекте. Более того, при помощи откровенной иронии рационализм англичан, одобряемый русским прогрессивным обществом, доводится до абсурда.

В «Политическом обозрении» майского номера приводится упоминание о прениях в английских палатах. Говорится, что иногда поднимаются интересные вопросы, вроде того, сколько военных сил у французов и сколько у англичан. Редакция подчеркивает, что после многочисленных подсчетов англичане успокаиваются, однако потом вновь начинают считать, испугавшись слухов о том, что у Франции есть броненосцы. Заканчивается данная часть обозрения фразой: «...но вместо того, чтобы так непроизводительно тратить громаднейшие капиталы, не лучше ли было бы обратить серьезное внимание на причину столь разорительных издержек и стараться истребить еe?» [Там же. С. 81].

Индивидуализм Англии и Европы в целом, с точки зрения редакции «Времени», разрушителен для личности и неминуемо ведёт к нравственному разложению общества на всех уровнях. Англия и Европа представляются очагом идеи современности о богатстве и накоплении, которая развращает человека.

К предисловию переведённого романа Мери Бартон «Повесть о манчестерских тружениках» даётся примечание: «Печатаем этот интересный роман потому, что в нём живо очерчены быт и страдания рабочего класса в Англии. Из всех европейских государств одна только Россия может смотреть с братским участием на все эти бедствия, на всю эту сословную ненависть, благодаря Богу ей самой вовсе неизвестные. Надел крестьян наших землею спасает нас навсегда от этой страшной, повсюду зияющей теперь язвы, которая называется “пауперизмом" или “пролетариатом"» [19. С. 523].

Пауперизм свойствен странам с развитой промышленностью. Это объясняется, с одной стороны, тем, что у любого человека есть потребности низшего порядка, которые он способен удовлетворить, отдавая взамен свой труд. Чем больше людей нуждаются в благе, тем мощнее производство, однако увеличение производительности за счёт количества трудящихся неэффективно и имеет свои последствия: чем больше людей населяет регион, тем больше рабочих мест они занимают, количество мест растёт, но и людей становится больше, соответственно, всё больше становится нищих.

С другой стороны, чем выше образование работника, тем труднее ему существовать в промышленном обществе. По мнению писателя, если человек развит 
духовно, материальные блага не будут для него столь привлекательны, соответственно, не будет необходимости в производстве промышленного масштаба, а значит, и бедноты.

Отмечается также, что уровень жизни в России значительно упал в связи с тем, что средний и высший классы российского общества стали недостаточно развиты духовно. В стремлении достичь большего было введено много технических преобразований, непосильных для России. Между тем добиться изобилия можно было бы исключительно путём возделывания земли. Другими словами, «Время» считает, что необходимы твёрдые нравственные основания и аскетизм. В этом случае общество будет сбалансировано [20. С. 33-49].

Редакция «Времени» отмечает, что принципиальная в своих убеждениях Англия, для которой главной ценностью является её народ, готова идти на преступления против своего народа, если это сулит выгоду.

В январском «Политическом обзоре» 1862 г. подводятся итоги прошедшего года. В это время конфликт между Севером и Югом в Штатах уже разгорелся, и предполагалось, что Англия вступит в войну. Американцы не хотели войны с Англией, однако виконт Пальмерстон и лорд Россель скрыли данную информацию и продолжили мобилизацию, заставляя тем самым народ нести огромные потери. «Время» жёстко осуждает поведение английских политиков: «Мирные намерения вашингтонского кабинета были несомненны; но их лордства продолжали делать военные приготовления, отправлять войска в Канаду и в своём величии равнодушно изволили взирать на упадок курсов $<\ldots>$. Неизвестно, в какой мере их лордства воспользовались упадком, но теперь, когда дело разъяснилось, оказывается несомненным, что игра была выгодная и очень крупная» [21. С. 7]. «Время» также подчеркивает, что во время хлопкового кризиса часть английских рабочих не получали зарплату, а хлеб при этом значительно подорожал. В то же время правительство устраивает всемирную выставку, оставляя «бедных рабочих» умирать от голода [21. С. 17].

Таким образом, в 1860-1861 гг. в крупных либеральных журналах XIX в. Англия представлена как мощная, развитая держава, которая считает нужным при помощи силы навязывать другим странам свои ценностные установки. Главная ценность для англичан - человеческие права, поэтому Англию можно назвать гуманной страной, и она готова бороться за свои принципы. Данный образ державы выстраивается публицистами в сравнении с Францией, которая обладает противоположными характеристиками: беспринципная, жестокая и меркантильная.

В связи со спецификой внутренней политической обстановки в России образ Англии на страницах либеральных журналов обретает назидательную функцию: исследуя прошлую и современную жизнь общества в Англии, его устройство, политическую систему державы, устройство университетов и многое другое, публицисты «намекали» российскому правительству, каким путём должна идти Россия.

Достоевский на страницах «Времени», выдерживая почвенническую позицию, последовательно критикует Запад, используя для этого выразителя, по мнению либеральных журналов, всей старой европейской культуры - Англию. Образ, представленный на страницах «Времени», противоположен образу «Современника», «Русского вестника» и «Отечественных записок»: Англия негуманна, непоследовательна, английский рационализм абсурден, а правительство ради выгоды допускает массовые смерти подданных. Писатель также разрушает оппозицию Англия - Франция и подводит их под общий знаменатель - «европейцы», выводя тем самым образ гуманной Англии на новый философский уровень. Достоевский и его единомышленники очерчивают связь между «математическим» гуманизмом, индивидуализмом и нравственным разложением европейского общества.

\title{
ПРИМЕЧАНИЕ
}

\begin{abstract}
${ }^{1}$ Так, И. Зохраб указывала на то, что Ф.М. Достоевский интересовался идеями английского философа-эмпирика Джона Стюарта Милля и, осмыслив, отчасти вкладывал их в уста героев своих художественных произведений [1. С. 37-52]. А.В. Денисова описала функции Лондона в формировании хронотопа «Зимних заметок о летних впечатлениях» [2. С. 64-74], о смысле образа Лондона в контексте этого произведения Достоевского пишет Е. Г. Новикова [3. С. 160-162]. В.Ю. Меринов на материале того же произведения и «Ряда статей о русской литературе» указал на особенности изображения Лондона в связи с формированием концептов «мы» - «они» [4. С. 107-118]. В.И. Габдуллина, в свою очередь, отметила, что в «Зимних заметках о летних впечатлениях», описывая Лондон как символ погибающей Европы, Ф.М. Достоевский актуализирует библейские апокалиптические коннотации [5. С. 13].
\end{abstract}

\section{ЛИТЕРАТУРА}

1. Зохраб И. «Европейские гипотезы» и «Русские аксиомы»: Достоевский и Джон Стюарт Милль // Русская литература. 2000. № 3. С. 37-52.

2. Денисова А.В. Функция хронотопа в «Зимних заметках о летних впечатлениях» Ф.М. Достоевского // Культура и текст. 2016. № 1 (24). C. 64-74.

3. Новикова Е.Г. «Nous serons avec le Christ». Роман Ф.М. Достоевского «Идиот». Томск : Изд-во Том. ун-та, 2016. С. $160-162$.

4. Меринов В.Ю. Приёмы создания концепта «другие» в философской публицистике Ф.М. Достоевского // Научные ведомости [Гуманитарные науки]. Белгород : Издательский дом «Белгород», 2010. № 12 (83), вып. 6. С. 107-118.

5. Габдуллина В.И. Искушение Европой: роман Ф.М. Достоевского «Игрок» // Вестник Томского государственного университета. 2008. № 314. С. 13-17.

6. Нечаева В.С. Журнал Достоевских «Время» 1861-1863. М. : Наука, 1972. 323 с.

7. Плоткин Л.А., Березина В.Г., Дементьев А.Г. Очерки по истории русской журналистики и критики. Л. : Изд-во Ленингр. ун-та им. Жданова, 1965. Т. 2. 516 с.

8. Политическое обозрение. Современная летопись // Русский вестник. М. : Издание М. Каткова, 1860. Т. 25 , кн. 1 и 2. С. 83-111.

9. Политика // Современник. СПб. : Типография Карла Вульфа, 1860. T. LXXIX (№ 2). С. 303-322.

10. Политическое обозрение // Отечественные записки. СПб. : Типография И.И. Глазунова и компании, 1860. Т. СХХХ. С. 44-60. 
11. Леность грубого простонародья. Современное обозрение // Современник. СПб. : Типография Карла Вульфа, 1860. T. LXXIX. (№ 2). C. $227-264$.

12. Повесть о Новой Зеландии. Иностранная литература // Отечественные записки. СПб. : Типография И.И. Глазунова и компании, 1860. T. CXXX. C. 40-42.

13. Политическое обозрение // Отечественные записки. СПб. : Типография И.И. Глазунова и компании, 1860. Т. СXXXI. С. $41-86$.

14. Мой дневник в Индии. Иностранная литература // Отечественные записки. СПб. : Типография И.И. Глазунова и компании, 1860. T. CXXIX. C. $1-18$.

15. О свободе. Иностранная литература // Отечественные записки. СПб. : Типография И.И. Глазунова и компании, 1860. Т. СХХVIII. С. 1-9. 16. Достоевский Ф.М. Ряд статей о русской литературе [Введение]. Критическое обозрение // Время. СПб. : Типография Эдуарда Праца, 1861. Т. 1. С. $1-34$.

17. Политическое обозрение // Время. СПб. : Типография Эдуарда Праца, 1861. Т. 1. С. 1-48.

18. Политическое обозрение // Время. СПб. : Типография Эдуарда Праца, 1861. Т. 3. С. 1-23.

19. Повесть о манчестерских тружениках. // Время. СПб. : Типография Эдуарда Праца, 1861. Т. 2. С. $522-583$.

20. Общее положение. Политическое обозрение // Время. СПб. : Типография Эдуарда Праца, 1861. Т. 5. С. $33-49$.

21. Англо-американские дела. Политическое обозрение // Время. СПб.: Типография Эдуарда Праца, 1862. Т. 7. С. 6-18.

Статья представлена научной редакцией «Филология» 25 февраля 2019 г.

Disputes About the Politics of England and France on the Pages of Russian Magazines of 1860-1862 and the Position of the Dostoevsky Brothers' Magazine Vremya

Vestnik Tomskogo gosudarstvennogo universiteta - Tomsk State University Journal, 2020, 451, 21-27. DOI: $10.17223 / 15617793 / 451 / 3$

Sofia V. Virovets, Tomsk State University (Tomsk, Russian Federation). E-mail: lizkakorejkina@gmail.com

Keywords: Dostoevsky; Pochvenichestvo; Vremya; Russkiy vestnik; Sovremennik; Otechestvennyie zapiski; image of England; image of France; Europe.

The aim of this study is to reconstruct the image of England, to determine its functions in the magazine Vremya in 1860 to 1862 , and to identify how the image of England changed compared with the one that had already been established in the above-mentioned magazines. England played a major role in the events that took place in Europe in the 1860s. This attracted the attention of Russian periodicals (Russkiy vestnik, Sovremennik, Otechestvennyie zapiski). Numerous publications about England together with the aggravated political situation in Russia made England a cult for the Russian intellectuals. A certain image of the country was formed. Dostoevsky, being a supporter of Pochvenichestvo (a movement closely tied with the ideology of the Slavophiles), saw danger in this trend. While approving of the reformation of the old way of life, Dostoevsky believed that Russia should work out a separate development path, different from the European one. At the time, England was making a great success in the foreign policy. A number of the largest Russian magazines indicated the need for reforms in Russia according to the English model. Dostoevsky considered this idea disastrous for the country. According to the controversy arising in this context, the image of England on the pages of Vremya performs certain functions and acquires a philosophical interpretation. In the early 1860s, England became the spotlight of Russian journalists due to the liberation movement in Italy and the issue of colonization. The current study is based on the articles connected with these topics. In the study, a comparative method is used to identify common and distinctive features of the image of England in magazines. The analysis of Russkiy vestnik, Sovremennik, Otechestvennyie zapiski showed the following features of the image. (1) In 1860-61, the major liberal magazines of the 19th century present England as a powerful, developed state, which considers it necessary to impose its values on other countries by force. (2) England is a country with a humanist ideology. It is ready to fight for its principles, but its humanism can be called rational: it puts its own interests above all and shows humanity if it sees benefit in it. (3) This image of England is built on a comparison with France, which is endowed with opposite characteristics. In the Vremya magazine, these characteristics are reinterpreted. The reconstruction of the image of England in the magazine and its comparison with the image in other magazines gave the following results. (1) England and France are equalled to Europe, thereby losing their national traits (the England-France opposition is destroyed). (2) England is not really a humane country since humanity cannot be dictated by the passion for profit. (3) European humanism, including the English one, is considered as a threat to the moral state of society and to every single person.

\section{REFERENCES}

1. Zokhrab, I. (2000) "Evropeyskie gipotezy" i "Russkie aksiomy": Dostoevskiy i Dzhon Styuart Mill' [“European Hypotheses" and "Russian Axioms": Dostoevsky and John Stuart Mill]. Russkaya literatura. 3. pp. 37-52.

2. Denisova, A.V. (2016) The Functions of Chronotop in "Winter Notes on Summer Impressions" by Fedor M. Dostoevsky. Kul'tura i tekst. 1 (24). pp. 64-74. (In Russian).

3. Novikova, E.G. (2016) "Nous serons avec le Christ". Roman F.M. Dostoevskogo "Idiot" ["Nous Serons avec le Christ." F.M. Dostoevsky's Novel "Idiot"]. Tomsk: Tomsk State University. pp. 160-162.

4. Merinov, V.Yu. (2010) Reception of the Concept "Others" in Philosophical Publicism of F.M. Dostoevsky. Nauchnye vedomosti Belgorodskogo gosudarstvennogo universiteta - Belgorod State University Scientific Bulletin. 12 (83):6. pp. 107-118. (In Russian).

5. Gabdullina, V.I. (2008) Temptation by Europe: The Novel "Gambler" by F.M. Dostoevsky. Vestnik Tomskogo gosudarstvennogo universiteta Tomsk State University Journal. 314. pp. 13-17. (In Russian).

6. Nechaeva, V.S. (1972) Zhurnal Dostoevskikh “Vremya” 1861-1863 [The Dostoevsky Brothers' Magazine Vremya. 1861-1863]. Moscow: Nauka.

7. Plotkin, L.A., Berezina, V.G. \& Dement'ev, A.G. (1965) Ocherki po istorii russkoy zhurnalistiki i kritiki [Essays on the History of Russian Journalism and Criticism]. Vol. 2. Leningrad: Leningrad State University.

8. Russkiy vestnik. (1860) Politicheskoe obozrenie. Sovremennaya letopis' [Political Review. Modern Chronicle]. 25:1-2. pp. 83-111.

9. Sovremennik. (1860) Politika [Politics]. LXXIX(2). pp. 303-322.

10. Otechestvennye zapiski. (1860) Politicheskoe obozrenie [Political Review]. CXXX. pp. 44-60.

11. Sovremennik. (1860) Lenost' grubogo prostonarod'ya. Sovremennoe obozrenie [Laziness of the Rude Common People. Contemporary Review]. LXXIX.(2). pp. 227-264.

12. Otechestvennye zapiski. (1860) Povest' o Novoy Zelandii. Inostrannaya literatura [A Story of New Zealand. Foreign Literature]. CXXX. pp. 40-42.

13. Otechestvennye zapiski. (1860) Politicheskoe obozrenie [Political Review]. CXXXI. pp. 41-86.

14. Otechestvennye zapiski. (1860) Moy dnevnik v Indii. Inostrannaya literatura [My Diary in India. Foreign Literature]. CXXIX. pp. 1-18. 
15. Otechestvennye zapiski. (1860) O svobode. Inostrannaya literatura [On Freedom. Foreign Literature]. CXXVIII. pp. 1-9.

16. Dostoevskiy, F.M. (1861) Ryad statey o russkoy literature [Vvedenie]. Kriticheskoe obozrenie [A Series of Articles on Russian Literature [Introduction]. Critical Review]. Vremya. 1. pp. 1-34.

17. Vremya. (1861) Politicheskoe obozrenie [Political Review]. 1. pp. 1-48.

18. Vremya. (1861) Politicheskoe obozrenie [Political Review]. 3. pp. 1-23.

19. Vremya. (1861) Povest' o manchesterskikh truzhenikakh [A Story of Manchester Workers]. 2. pp. 522-583

20. Vremya. (1861) Obshchee polozhenie. Politicheskoe obozrenie [General Situation. Political Review]. 5. pp. 33-49.

21. Vremya. (1862) Anglo-amerikanskie dela. Politicheskoe obozrenie [Anglo-American Affairs. Political Review]. 7. pp. 6-18.

Received: 25 February 2019 